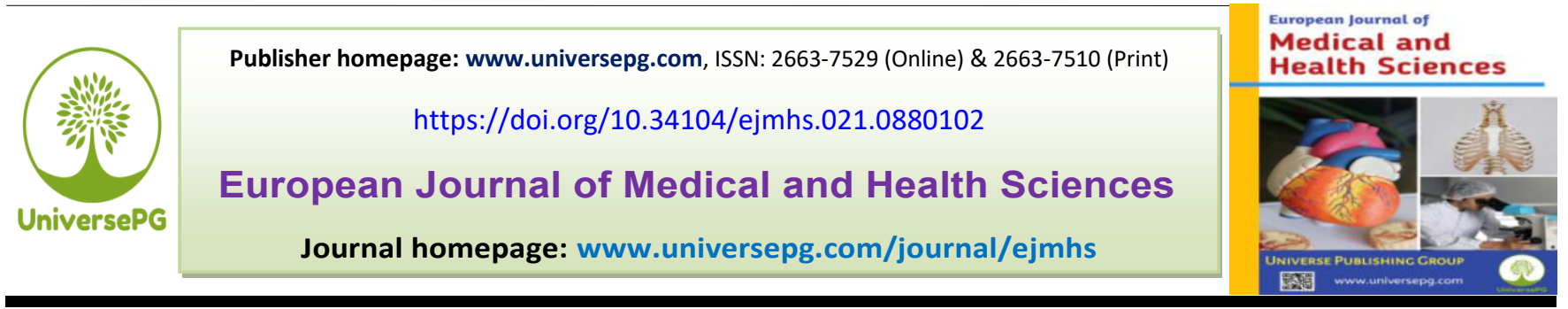

\title{
Prevalence of Physical Activity with Mobility Disabilities among Senior Citizens in a Selected Old Home
}

\author{
Md. Omar Sharif Ahmmed Chowdhury ${ }^{1 *}$, Rumpa Khatun ${ }^{2}$ and Sukrana Pervin ${ }^{3}$ \\ ${ }^{1}$ Department of Physiotherapy, Gono Bishwabidyalay, Dhaka, Bangladesh; ${ }^{2}$ Department of Physiotherapy, Gono Bishwa- \\ bidyalay, Dhaka, Bangladesh; and ${ }^{3}$ Department of Drama \& Dramatics, Jahangirnagar University, Dhaka, Bangladesh. \\ *Correspondence: oschowdhury33@gmail.com (Md. Omar Sharif Ahmmed Chowdhury, Assistant Lecturer, Department of \\ Physiotherapy, Gono Bishwabidyalay, Savar, Dhaka, Bangladesh).
}

\begin{abstract}
The purpose of the study was to identify the mobility problem of aged people in selected old homes. The ages of the respondents are 60 plus age, which is clustered into 3 age groups 60-69 years, 70-79 years, and 80 plus age. This study established among $100 \%$ respondents $89.3 \%$ have self-bathing capacity, $89.3 \%$ have self-dressing capacity, $89.8 \%$ have self-toileting capacity, $93.3 \%$ have self-teeth washing capacity, $93.7 \%$ have self-eating capacity. For finding other problems of aged people set up among 206 participants of old home area, 35.0\% are disability problem. Besides, in old homes $19.9 \%$ have suffered diabetic mellitus for a long time, $51.0 \%$ suffered from hypertension, $11.7 \%$ suffered from low blood pressure, $14.6 \%$ have heart problems, $64.6 \%$ have urine catching difficulty, 6.8\% have kidney disease. Among 206 respondents of the old home, area were $44.2 \%$ abnormal posture and they having $36.9 \%$ kyphosis, $4.4 \%$ scoliosis $0.5 \%$ lordosis, and $2.4 \%$ another abnormal posture. For the finding of aged people, we have asked some questions to identify pain severity and several labels found that among 206 participants of the old home area were 52.4\% have pain during straight walking, $36.9 \%$ have neck pain, $56.3 \%$ have hip pain or lower back pain, 28.6\% have thoraco-lumber pain and $34.0 \%$ have pain during sleeping time. Besides on these area respondents there was pain severity $21.4 \%$ have mild pain, $22.3 \%$ have moderate pain and $24.8 \%$ have severe pain. In this paper among 206 respondents of the old home area was $10.7 \%$ having a stroke history. Here $3.4 \%$ right side, 4.4 left sides, both sides $2.9 \%$ paralyzes. In this study Right shoulder motion $56.8 \%$ of participants ROM under 150 degrees and Left shoulder motion $61.2 \%$ of participants ROM under 150 degrees. Conversely, Right hip motion was $27.7 \%$ of participants ROM under 60 degrees, and Left hip motion 30.6\% of participants ROM fewer than 60 degrees. Besides, Right knee motion $56.8 \%$ of participants ROM under 120 degrees and Left knee motion 57.3\% under 120 degrees. In the current study we think that everyone should take responsibility to survive the aged people for a long time.
\end{abstract}

Keywords: Physical activity, Mobility, Disabilities, Prevalence, ROM, Old home, and Senior citizen.

\section{INTRODUCTION:}

Aging with Disability rates are anticipate increasing with the human population (Seeman et al., 2010). The prevalence of ADL in disability contributory activities and increase mobility for those 60-69 years aged people actually suggest data, recent National Health and NutUniversePG I www.universepg.com rition Examination Survey (NHANES) (Brault et al., 2009). The healthcare process, public health authorities, rehabilitation, medicine dispensary could overcome of the future burden. Even though many physical activity researches has concentrate on old peoples who are free of illness, impairment and disability, the required con- 
tinuously exists for a healthy ageing research agenda to old peoples with disability for purpose of prevention. Health promoting aging within senior citizen who has disabilities has been neglected. Senior citizens with disabilities can convenience from living in consequence model with a healthy ageing life that comprises "the maintenance and improvement of optimal physical, psychological and social well-being and function". (Physical Activity Guidelines Advisory Committee Report, 2008) General physical, psychological health may be improved while the underlying disability cannot be reversible. The aim of the study is discuss to the physical activity with mobility among senior citizen in Bisia old home.

The UN with whole world celebrate International elderly day of aged person is on October 1 every year (Jason et al., 2006). Like several numerous countries, Bangladesh also observed the day with different programs and activities with aged people Rimmer et al. (2010). But, thereat nothing internationally accepted age bracket for defining the senior citizens, people aged 60 years or above are considered as elderly in most erotological literature. Bunuales et al. (2002) Elderly population in the context of Bangladesh has been defined as who has reached 60 years of age. Prohaska et al. 2006) they establish rotary forward framework around four questions on physical activity and ageing to help feature the public health research agenda. The objective of the current study is promoting activity amid aged people with disability using a framework on a research agenda to organize. They describe four topic areas in that study, based on the framework of: Observation data on the prevalence of ADL within senior citizen with disability; Inspection of convenience the health in activity and the outcome of sedentary behavior in aged people with disability; Correspond and definitive of activity participated within senior citizen with mobility disability; and Auspicious intermediate obtainment for improving physical activity in ageing peoples with mobility disability.

Whilst are many grade of disability including mobility, sensory, behavioral, cognitive, or psychological disabilities (Aftab et al., 1999) in this paper they concentrate on mobility disability. In this paper Mobility disability is defined by them as happen "whereas impairments in mobility limit the efficacy of individuals UniversePG I www.universepg.com to move in their natural environment in order to carrying out activities important to daily life."The International Functional Classification (ICF) framework extensively defined health conditions that may lead to physical functions and structure, ADL, and participate changing as "disorders, injuries, aging, and birth abnormality" (Alan and Joga, 2009) consequently, while they used examples, they consider mobility disability to be causes into many several factors. So, individuals can be birth with or is revealed mobility disability earlier in life and are ageing with these conditions. Moreover, as like people age, chronic diseases such as cardiovascular, diabetes, stroke, arthritis may lead to disability. At last, functional disability may be caused by a unaccompanied, identifiable condition for example multiple sclerosis (MS) or a trauma which resulted in SCI (Field and Jette, 2007) but may also be diluted by development of chronic condition found in senior citizen (Arksey and Malley, 2005). Nevertheless of the etiology, there is a necessary to physical activity improvement for those with various types of disease that leading to mobility disability. They include in this review both aged persons with disable conditions, for example movement difficulty, and more general conditions that lead to disabilities. Though this paper concentrate on mobility disable person, this study will recapitulate research in the physical disable aged person, where data are lacking or when definition are unclear.

Mobility problem on insufficient functional activity is the commonest problem in senior citizens. Worldwide, $80 \%$ of population suffering more in mobility problem (Lollar, 2002). Many aged peoples are suffered many health related problem and worst complications like as respiratory illness, musculoskeletal pain, bony deformity, postural deformity, neurological problem, behavioral \& cognitive problem, gait and ADL problem because of prolong inactivity (Roy et al., 2020). Schneider and Meyer, (2015) the main purpose of therapeutic intervention is prevented the complications of ageing peoples and give a quality life (Garriga et al., 2014). This study will also help to discover, especially about their posture before doing any activities. Beside this it will help to professional development which is mandatory for current situation. Also help Aged people to increase awareness maintain right position, lifestyle, 
how to stay more active and they manage their ADL easily. In the study researcher can identify the risky factors of the work-place which are harmful. So investigators can help them to teach and give proper education about mobility and postural condition and preventive methods. By this there will develop a good relationship with Physiotherapist and as well as other medical professionals, which is very important in current study approach. And it will help to discover the importance of physiotherapy in every sector of Bangladesh. Physiotherapy focused on pain management with strength of muscle. Conventional exercise is helpful to reduce pain and increase the joint range.

\section{Literature Review}

In the year of February 2016 to conduct a study in Germany to find out the Outcomes of laboratory-based tests for mobility is often used performance in real life to infer about older peoples. Their presumption on capacity of mobility, as measurement in real life mobility performance. Total 84 aged peoples consists the sample and evaluation of capacity by gait parameters. All lab measurement was evaluated by the reallife measurement. All measurement calculated indicates for an important but ratio of variance are very low (within $5 \%$ and $21 \%$ ) by the various regress analyses. In the year of 2006 in Finland, They observed as risks for institutionalization and find out the Mobility limitations and cognitive disorders. However primarily community-residency senior citizen has been low good reported in their collective effects on hazard of establishment. Their Study sample $(n=476)$ are consist community-residency 75- and 80-year- aged peoples participated for experiments on cadence, walking speed and brain capacity on the center. Mobility is measure on 10-m distance in walking speed. Monopolistic distribution based study were made by cut-offs the lesser as follows: small movement limitation, solely psychological deficits, and ADL limitation. Institutionalized participants were $11 \%$ during surveillance in the 10-year. There was 4.9 times greater risk $(95 \%$ dependence interval: 2.1-11.2) for who had accompany movement limitation and psychological deficits than. In the year of 2015 to conduct a study in Finland towards discover the Mobility and activity problem as Predictors of fatality and increase dependency in the Community Living Older Population. Peoples were 1109 living independently, selected people at 65 to 84 year old in Finland. The comparative risk of mortality was double large time in Impaired Active and triple large times in Impaired Sedentary community group than hazard of mortality in Mobile Active population groups. The unusual proportion for dependability (95\% dependence interval) in Impaired Sedentary men and women ratio was $5.21(1.44-18.70)$ and 2.92 (1.525.60) compared to Mobile Active population. The hazard of confidence is not different significantly among Mobile Active, Mobile Sedentary, and Impaired Active groups. In the year of 2004 to conduct a study in Birmingham to find out Association within ocular observation and activity in senior citizens. Their study had Three hundred forty two older adults (aged 55-85) living independently in social recruited from health with ADL information on mobility: a test of visual attention/processing speed; Function and self reported measures of falls, falls efficacy, mobility/balance, performance measure by mobility assessment. Poorer scores on visual attention/processing speed were significantly involved to the mobility assessment performance for age, sex, race, education, number of chronic disease, psychological status, depression, visual defect, and sensory contrast $(\mathrm{P}=.04)$ after coordination.

Iris et al. (2015) conducts a study in England towards discover functional activity is the basis for participation and social life. They assess ADL activity with functional status are prone to decline the older hospitalized patients (Rana et al., 2021). All admitted to residential care older patients are mandatory and avoid decrease dependency of mobilization and activation. In the year of November, 2011 to conduct a study in New Zealand to find out A literature of evidence on functional activity for ageing people and a reconsideration of existing contributors Senior Researcher New Zealand they show strongest evidence for the benefits of physical activity related heart disease, stroke, degenerative disease, depression, obesity for older people in the management of health and disability. They show to strong records exists to The importance of functional activity for aging people in enhancing physical fitness, wellbeing, cognitive function, and physical function. In the year of November, 2018 to conduct a study in Zambia to find out a community-based physical activity intervention to prevent mobility-related disability for 
retired older people. The aim of systematic review was to examine of senior citizen on their functional mobility with ADL and effects of functional training on muscle strength. Aims to test the effectiveness in senior citizen and cost-effectiveness of a social group-wise ADL activity interfere for decreasing who are at large hazard of mobility related disability of their development of ADL limitations.

\section{Research Question}

Are the statuses of senior citizens activity related disabilities in old home?

\section{Study Objectives}

General Objective - To find out the mobility with activity related disabilities of senior citizen in selected old home.

\section{METHODOLOGY:}

Conceptual Framework

\begin{tabular}{|l|c|}
\hline Independent Variable & Dependent Variable \\
\hline Socio-Demographic Factors & \\
Sex, Religion, Age, Education, Occupation, Monthly Income, Children, Stay old home & \\
\hline Activity Related Variables & \\
Bathing, Dressing, Toileting, Teeth washing, Taking food, Spend maximum time. & Physical Activity with \\
\hline Health Problem factor related & Mobility Disabilities \\
Deformity, Device use, Diabetics, Blood pressure, Heart problem, Urine catching difficulty, \\
Kidney disease, Stroke History. & \\
\hline Pain Related & \\
Posture, Pain history, Pain severity. & \\
\hline Measurement of ROM & \\
\hline Shoulder joint, Elbow joint, Hip joint, Knee joint. & \\
\hline
\end{tabular}

Study Plan and Area - This is an Experimental study. The study was conducted at Hotapara old home in Gazipur district.

Target Respondent and Study Period - Respondent of this study is people, whose ages are 60+ (above 60) agreeing to give information of their own accord. The study population will consist of both Male and Female in selected old home. January 1, 2020 to May 30, 2020.

Sample Size - 206 subjects selected by maintenance of exclusion and inclusion criteria.

\section{Inclusion criteria}

a) Subjects who are above 60 years old.

b) Both sexes are involved.

c) Subject who have functional difficulties

d) Who are willing to give consent and participate?

\section{Specific Objectives}

a) To find out the socio-demographic factors of the respondents.

b) To analyze the deformity of the respondents.

c) To find out health related problem of the respondents.

d) To find out the psychological problem of the respondents.

\section{Limitations of the Study}

There were some limitation and barriers during conducting the study project. They are as mention below:

1) Number of question was selected.

2) Sample size is small but chosen purposively.

\section{Exclusion Criteria}

a) Subject who are not stay on old home.

b) Subject who are under 60 years old.

c) Subject who are not willing to give consent and participate.

Sampling Technique - Purposive random sampling technique was applied.

Data collection tools - A structured questionnaire was developed for the research purpose, then an orientation was conducted among collectors with field test and finally the data was collected by going door to door of aged people on that questionnaire. In old home area we take their permission and measure some main joints motion by goniometry. The current studies we measure on differentiate various level of all motion. 
Data Management \& Analysis Plan - The respondents were organized of data after collection. After collection data was entered into the computer in a data base software package. SPSS 23.0 version use for narrative statistics for example frequency, ordination, mean and percentage. All scores and percentages were computed and presented in tabular form, charts and graphs as appropriate. Chi-square test and P-value will help further it was analyzed. Finally, interpreted the data on the basis of study findings.

Quality Control \& Quality Assurance - This preliminary study has a numeral limitation. The experimental study was risk for the respondents. The population size was comparatively small due to financial constraints in this study period and thus the result is not being generalized.

Ethical consideration - The motive and goals toward with its benefits, risks and procedure were explained of the study to the respondents in easily. Information was accepted from every respondents by use perceive native language. The researcher first introduced himself with respondents. Then the researchers will give them the assurance that the information of the responders will be usage just for the research purpose. The researchers tell

Table 1: Distribution of respondents by sex.

\begin{tabular}{|c|c|c|c|}
\hline \multicolumn{2}{|c|}{ Sex } & Number & Percentage \\
\hline \multirow{3}{*}{ Valid } & Male & 106 & 51.5 \\
\cline { 2 - 4 } & Female & 100 & 48.5 \\
\cline { 2 - 4 } & Total & 206 & 100.0 \\
\hline
\end{tabular}

Table 3: Distribution of respondents by Age in year.

\begin{tabular}{|l|c|c|c|}
\hline \multicolumn{2}{|l|}{ Age } & Number & Percentage \\
\hline \multirow{3}{*}{ Valid } & $60-69$ years & 97 & 47.1 \\
\cline { 2 - 4 } & $70-79$ years & 76 & 36.9 \\
\cline { 2 - 4 } & $80+$ & 33 & 16.0 \\
\cline { 2 - 4 } & Total & 206 & 100.0 \\
\hline
\end{tabular}

Table 4: Distribution of respondents by Occupation.

\begin{tabular}{|c|c|c|c|}
\hline \multicolumn{2}{|c|}{ Occupation } & Number & Percentage \\
\hline Valid & Business & 24 & 11.7 \\
\cline { 2 - 4 } & Job & 59 & 28.6 \\
\cline { 2 - 4 } & Farmer & 15 & 7.3 \\
\cline { 2 - 4 } & Day labor & 4 & 1.9 \\
\cline { 2 - 4 } & Others & 104 & 50.5 \\
\cline { 2 - 4 } & Total & 206 & 100.0 \\
\hline
\end{tabular}

UniversePG I www.universepg.com them that their name will be hidden secret. All kind of privacy is confirmed and any resections from the respondent are first priority. They also told this information will only use for benefit of Physiotherapy profession and the improve health with decrease occupational hazard.

\section{RESULTS:}

The Following Table 1 explained about the ratio of sex of respondent in selected Old home. Here among the 206 respondents in this place. In this place the ratio is $51.5 \%$ and $48.5 \%$ male female respectively. The Table 2 shows the distribution of religion of respondent in Selected Old home. It shows that all respondent are Muslim $87.9 \%$, Christian $1.5 \%$ and Hindu $10.7 \%$. The Table 3 explained the distribution of respondents by age in year. Here we have seen that most respondents in selected old home are $60-69$ years in $47.1 \%, 36.9 \%$ are $70-79$ years and $16 \%$ respondents are above 80 years old. Table 4 explained the distribution of respondents by occupation in selected old home in my study. Among 206 respondents in old home area there were $11.7 \%$ businessman, $28.6 \%$ were job holder, $7.3 \%$ were farmer, $1.9 \%$ were day labor and other occupation were $50.5 \%$.

Table 2: Distribution of respondents by Religion.

\begin{tabular}{|c|c|c|c|}
\hline \multicolumn{2}{|c|}{ Religion } & Number & Percentage \\
\hline \multirow{4}{*}{ Valid } & Islam & 181 & 87.9 \\
\cline { 2 - 4 } & Christian & 3 & 1.5 \\
\cline { 2 - 4 } & Hindu & 22 & 10.7 \\
\cline { 2 - 4 } & Total & 206 & 100.0 \\
\hline
\end{tabular}

Table 5: Distribution of respondents by Educational level.

\begin{tabular}{|c|c|c|c|}
\hline \multicolumn{2}{|c|}{ Educational level } & Number & Percentage \\
\hline \multirow{4}{*}{ Valid } & Primary & 41 & 19.9 \\
\cline { 2 - 4 } & SSC & 37 & 18.0 \\
\cline { 2 - 4 } & HSC & 9 & 4.4 \\
\cline { 2 - 4 } & College Graduate & 11 & 5.3 \\
\cline { 2 - 4 } & University & 4 & 1.9 \\
\cline { 2 - 4 } & Vocational Education & 3 & 1.5 \\
\cline { 2 - 4 } & No Education & 101 & 49.0 \\
\cline { 2 - 4 } & Total & 206 & 100.0 \\
\hline
\end{tabular}

In addition $19.9 \%$ respondents were primary level, $18 \%$ SSC level, 4.4\% HSC level, 5.3\% college level, 1.9\% University level, $1.5 \%$ vocational education level and 49\% respondents were no education level (Table 5). 
Table 6: Distribution of respondents by Income.

\begin{tabular}{|c|c|c|c|}
\hline \multicolumn{2}{|c|}{ Income } & Number & Percentage \\
\hline \multirow{3}{*}{ Valid } & Yes & 18 & 8.7 \\
\cline { 2 - 4 } & No & 188 & 91.3 \\
\cline { 2 - 4 } & Total & 206 & 100.0 \\
\hline
\end{tabular}

Table 7: Distribution of respondents by Children.

\begin{tabular}{|c|c|c|c|}
\hline \multicolumn{2}{|c|}{ Children } & Number & Percentage \\
\hline Valid & Yes & 153 & 74.3 \\
\cline { 2 - 4 } & No & 53 & 25.7 \\
\cline { 2 - 4 } & Total & 206 & 100.0 \\
\hline
\end{tabular}

Table 8: Distribution of respondents by Stay in the old home.

\begin{tabular}{|c|c|c|c|}
\hline \multicolumn{2}{|c|}{ Stay in old home } & Number & Percentage \\
\hline Valid & Under 1 year & 55 & 26.7 \\
\cline { 2 - 4 } & 1-2 years & 58 & 28.2 \\
\hline \multirow{4}{*}{} & 3 years or above & 93 & 45.1 \\
\cline { 2 - 4 } & Total & 206 & 100.0 \\
\hline
\end{tabular}

Table 9: Distribution of respondents by Take bath regular independently.

\begin{tabular}{|c|c|c|c|}
\hline \multicolumn{2}{|c|}{ Self-bathing capacity } & Number & Percentage \\
\hline Valid & Yes & 184 & 89.3 \\
\cline { 2 - 4 } & No & 22 & 10.7 \\
\cline { 2 - 4 } & Total & 206 & 100.0 \\
\hline
\end{tabular}

Table 10: Distribution of respondents by wearing Dress independently.

\begin{tabular}{|c|l|l|l|}
\hline \multicolumn{2}{|c|}{ Self-dressing capacity } & Number & Percentage \\
\hline Valid & Yes & 184 & 89.3 \\
\cline { 2 - 4 } & No & 22 & 10.7 \\
\cline { 2 - 4 } & Total & 206 & 100.0 \\
\hline
\end{tabular}

Table 11: Distribution of respondents by use toilet independently.

\begin{tabular}{|c|c|c|c|}
\hline \multicolumn{2}{|c|}{ Self-toileting capacity } & Number & Percentage \\
\hline Valid & Yes & 185 & 89.8 \\
\cline { 2 - 4 } & No & 21 & 10.2 \\
\cline { 2 - 4 } & Total & 206 & 100.0 \\
\hline
\end{tabular}

Table 12: Distribution of respondents by washes teeth regular independently.

\begin{tabular}{|l|l|l|l|}
\hline \multicolumn{2}{|l|}{ Self-teeth cleaning capacity } & Number & \multicolumn{1}{c|}{ Percentage } \\
\hline \multirow{3}{*}{ Valid } & Yes & 192 & 93.2 \\
\cline { 2 - 4 } & No & 14 & 6.8 \\
\cline { 2 - 4 } & Total & 206 & 100.0 \\
\hline
\end{tabular}

Table 13: Distribution of respondents by Take food himself.

\begin{tabular}{|c|c|c|c|}
\hline \multicolumn{2}{|c|}{ Self-eating capacity } & Number & Percentage \\
\hline Valid & Yes & 193 & 93.7 \\
\cline { 2 - 4 } & No & 13 & 6.3 \\
\cline { 2 - 4 } & Total & 206 & 100.0 \\
\hline
\end{tabular}

UniversePG I www.universepg.com

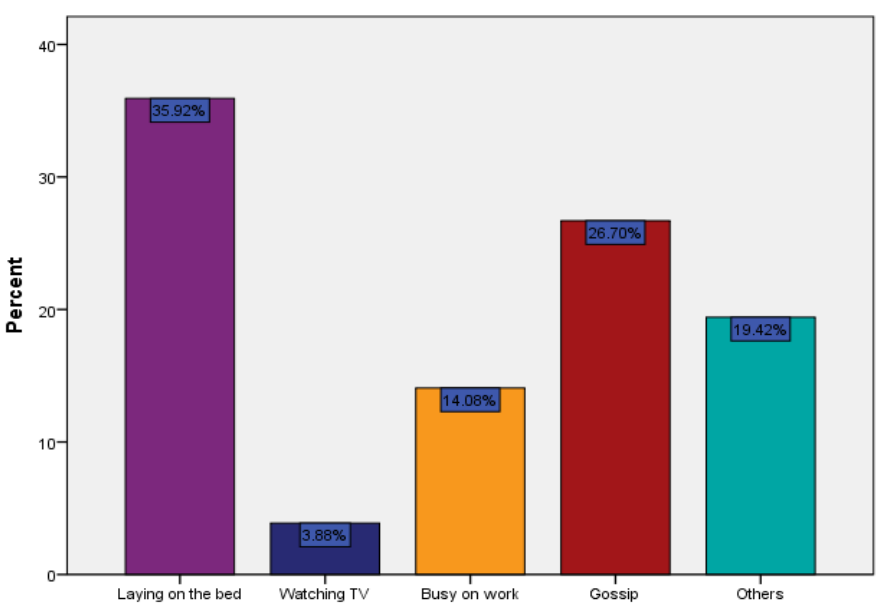

Fig 1: Distribution of respondents by Spend maximum time in a day.

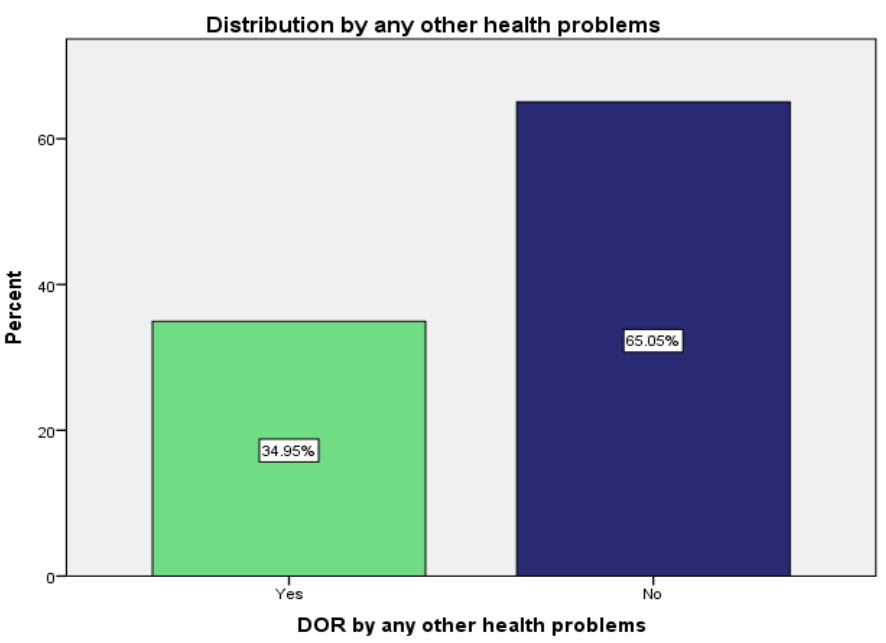

Fig 2: Distribution of respondents by has another health problem.

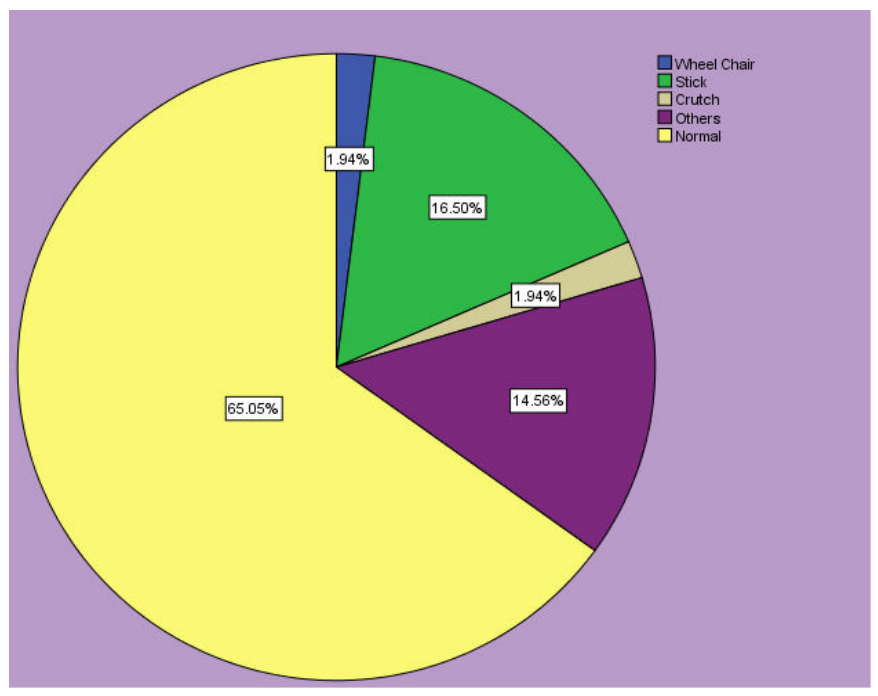

Fig 3: Distribution of respondents by Use mobility aid for health problem. 
The following Table 6 explained the distribution of respondents by personal income in selected old home. Among 206 respondents in old home area were 8.7\% income yes and $91.3 \%$ were no income.

The following Table 7 explained the distribution of respondents by children in our study. Among 206 respondents in old home area were $74.3 \%$ having children yes and $25.7 \%$ haven't any children.

The following Table 8 explained the distribution of respondents by stay in the old home (year) in our study. Among 206 respondents in old home area were 26.7\% stay under 1 year, $28.2 \%$ were stay $1-2$ years and $45.1 \%$ were stay in 3 years or above.

The following Table 9 explained the distribution of respondents by take bath independently and regularly. Among 206 respondents in old home area were 89.3\% taken bath regular independently and $10.7 \%$ nothing take bathing regular independently.

The following Table 10 explained the distribution of respondents by wearing dress independently. Among 206 respondents in old home area were $89.3 \%$ wearing dress independently and $10.7 \%$ nothing to wearing dress independently.

The following Table 11 explained the distribution of respondents by use toilet independently. Among 206 respondents in old home area were $89.8 \%$ use toilet

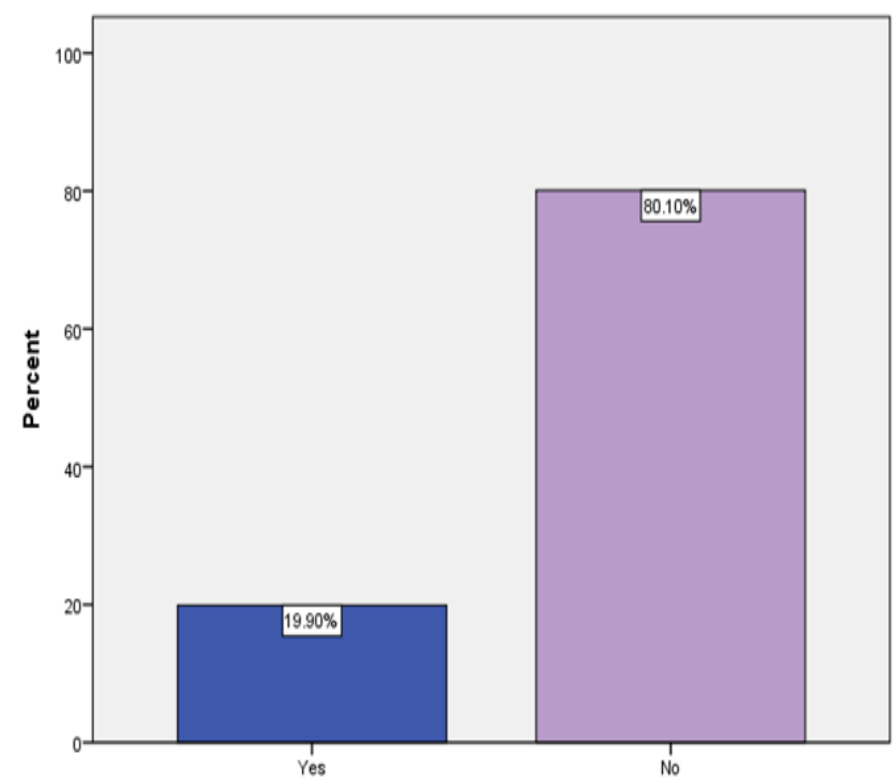

Fig 4: Distribution of respondents by you have or haven't Diabetics. independently and $10.2 \%$ nothing to use toilet independently.

The following Table 12 explained the distribution of respondents by wash teeth regular independently. Among 206 respondents in old home area were 93.2\% wash teeth regular independently and $6.8 \%$ nothing wash teeth regular independently.

The following Table 13 explained the distribution of respondents by Take food himself independently. Among 206 respondents in old home area were 93.7\% taken food himself regularly and $6.3 \%$ nothing take food himself regularly.

From the above Fig 1 explained the distribution of respondents by spend maximum time in a day. Among 206 respondents in old home area were $35.9 \%$ laying on the bed, $3.9 \%$ watching TV, $14.1 \%$ busy on work, $26.7 \%$ gossip and $19.4 \%$ others activities.

From the above Fig 2 explained the distribution of respondents by have any other health problem in our study. Among 206 respondents in old home area were $35 \%$ having another health problem and 65\% haven't any other health problem.

From the above Fig 3 explained the distribution of respondents by use device for health problem in our study. Among 206 respondents in old home area were $1.9 \%$ use wheel chair, $16.5 \%$ use stick, $1.9 \%$ crutch and $14.6 \%$ use another device for health problem.

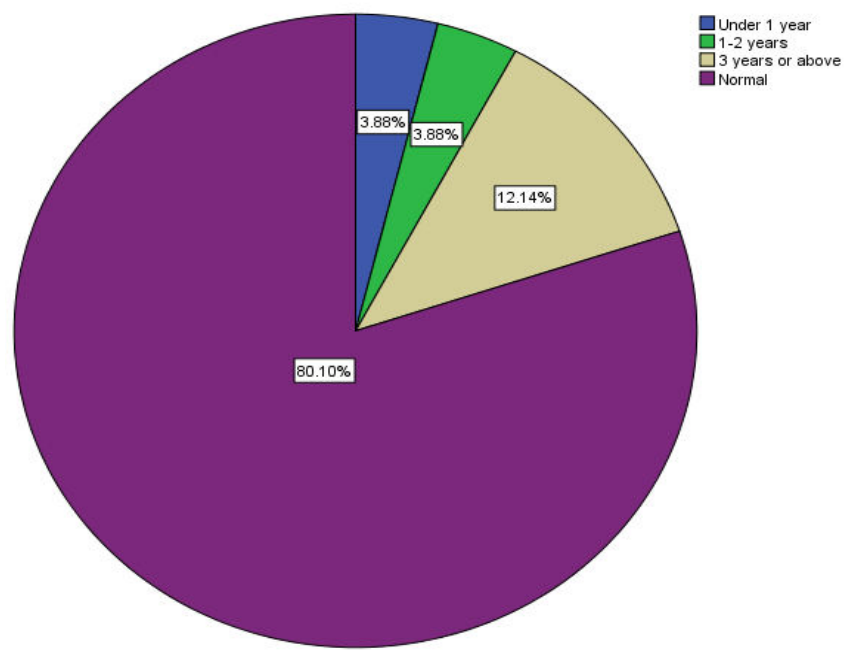

Fig 5: Ordination of respondents by present Diabetes, how long. 
From the above Fig 4 explained the distribution of respondents by have or haven't Diabetics in our study. Among 206 respondents in old home area were 19.9\% having Diabetics and $80.1 \%$ haven't Diabetics.

From the above Fig 5 explained by present Diabetes or not. If present, how long pass away. Among 206 respondents in old home area were $3.88 \%$ have under 1 year, $3.88 \%$ have $1-2$ years, $12.14 \%$ have 3 years or above and $80.1 \%$ haven't Diabetics.

From the above Fig 6 explained by present Blood pressure in the study. Among 206 respondents in old

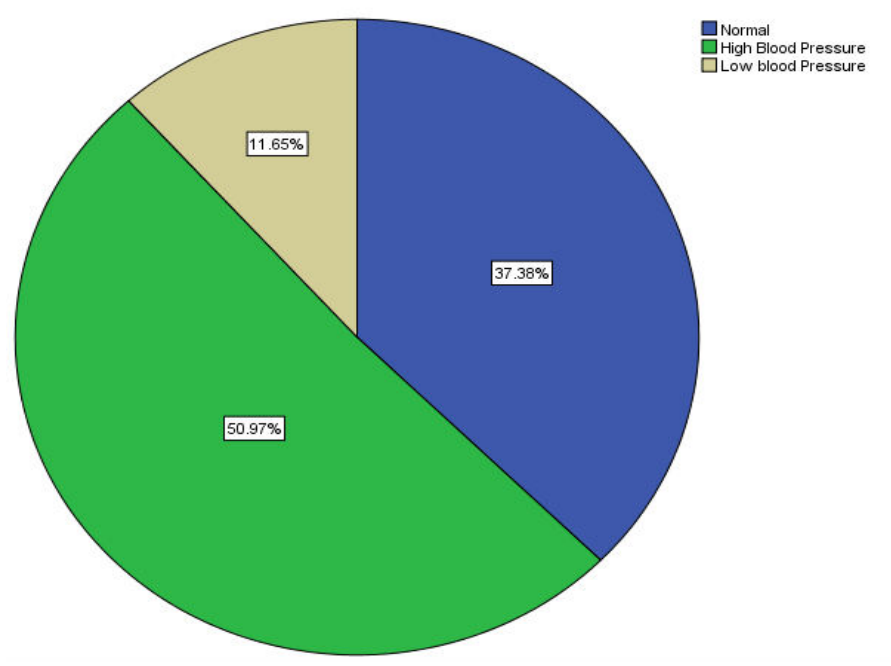

Fig 6: Ordination of respondents by Blood Pressure.

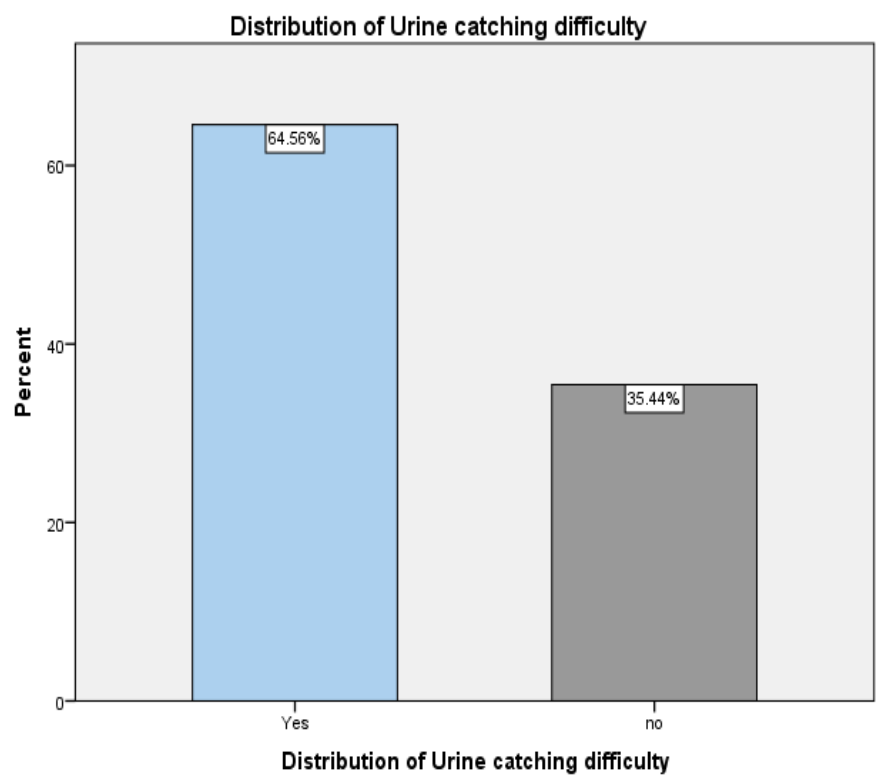

Fig 8: Respondents distribute by Urine catching difficulty. home area were $37.4 \%$ normal blood pressure, $51.0 \%$ have hypertension and $11.7 \%$ have low blood pressure.

From the above Fig 7 explained by Heart problem in this study. Among 206 respondents in old home area were $14.6 \%$ having heart problem and $85.4 \%$ haven't heart problem.

From the above Fig 8 explained by Urine catching difficulty in our study. Among 206 respondents in old home area were $64.6 \%$ have Urine catching difficulty $35.4 \%$ haven't Urine catching difficulties.

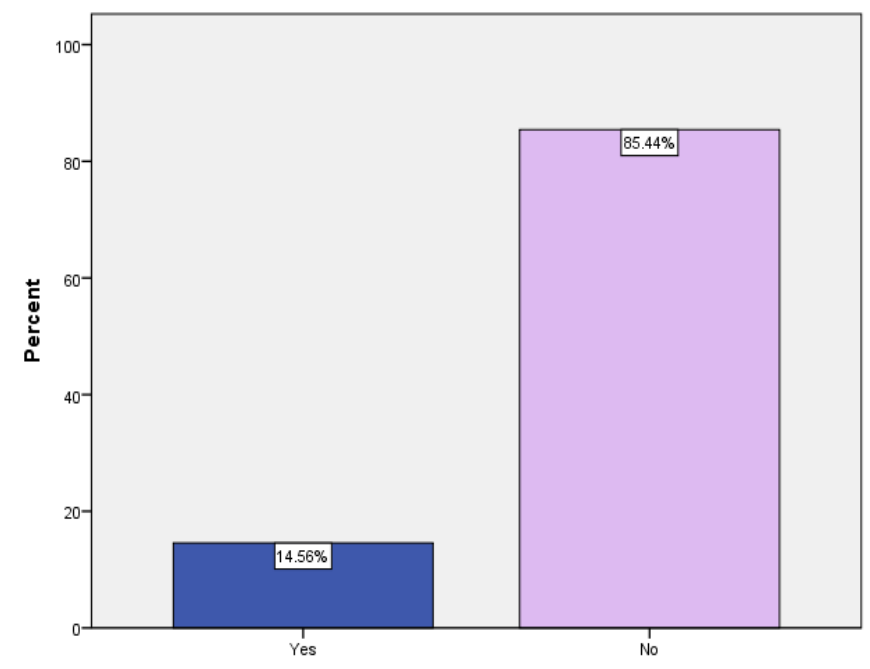

Fig 7: Respondents ordination by Heart problem.

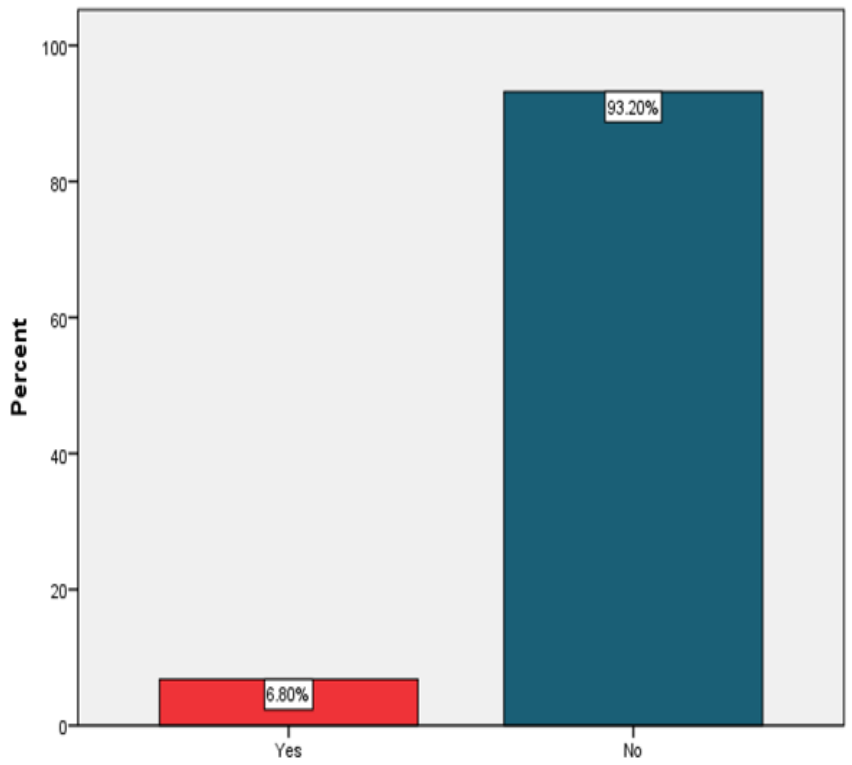

Fig 9: Respondents ordinate by Kidney Disease. 
From the above Fig 9 explained about Kidney disease. Among 206 respondents in old home area were $6.8 \%$ having kidney disease and $93.2 \%$ haven't kidney disease.

From the above Fig 10 explained by Posture in current study. Among 206 respondents in old home area were $55.8 \%$ having normal posture and $44.2 \%$ abnormal posture.

From the above Fig 11 explained the variety of postural abnormality in our study. Among 206 respondents in old home area were $36.9 \%$ Kyphosis, $4.4 \%$ Scoliosis,

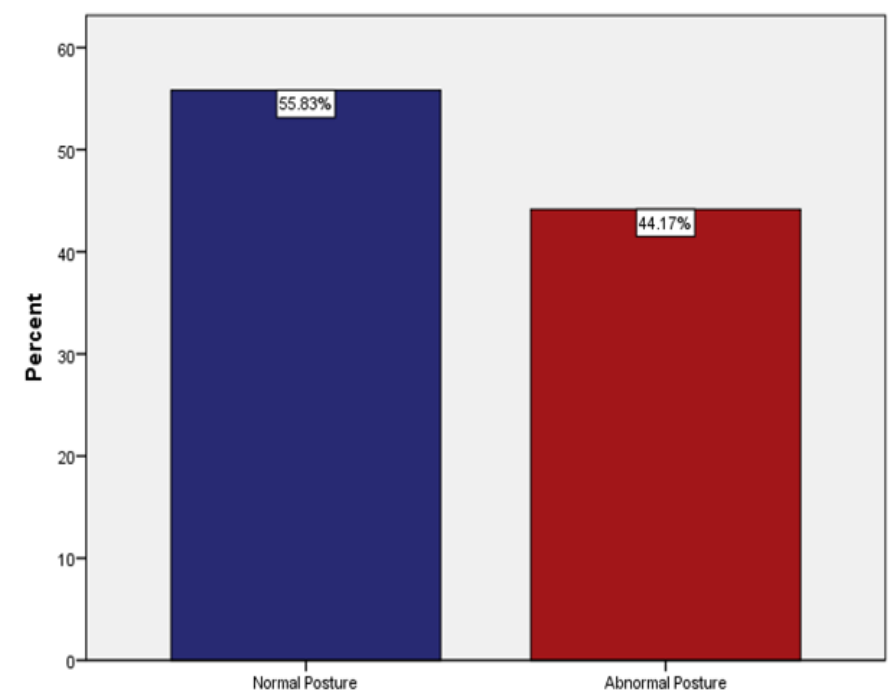

Fig 10: Ordination of respondents by Posture.

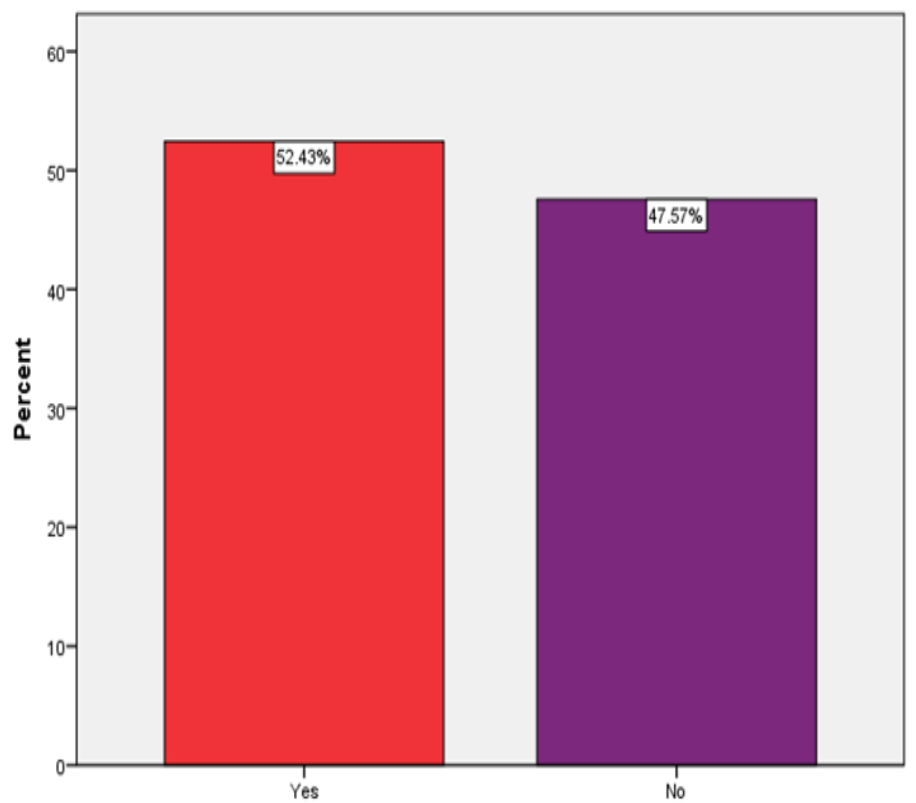

Fig 12: Distribution of respondents by felling any pain during walking.

UniversePG I www.universepg.com
$0.5 \%$ Lordosis, $2.4 \%$ others and $55.8 \%$ haven't any postural abnormality.

From the above Fig 12 explained the distribution of respondents by felling any pain when walking in straight line. Among 206 respondents in old home area were $52.4 \%$ having pain and $47.6 \%$ haven't felling any pain when walking.

From the above Fig 13 explained the Lower back pain in our study. Among 206 respondents in old home area were $56.3 \%$ having lower pain and $43.7 \%$ haven't Hip pain.

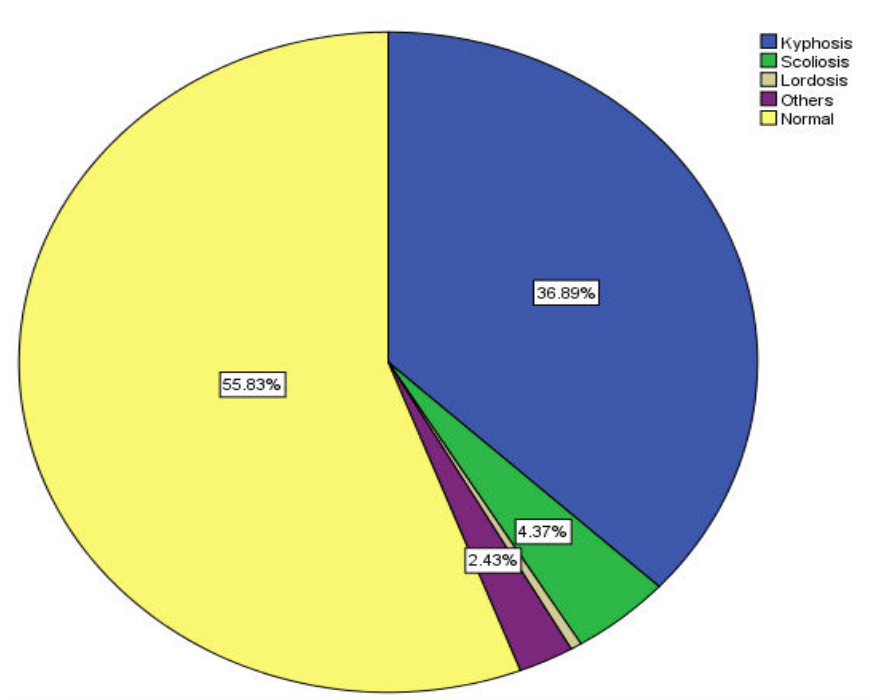

Fig 11: Respondents distributed by Variety of postural abnormality.

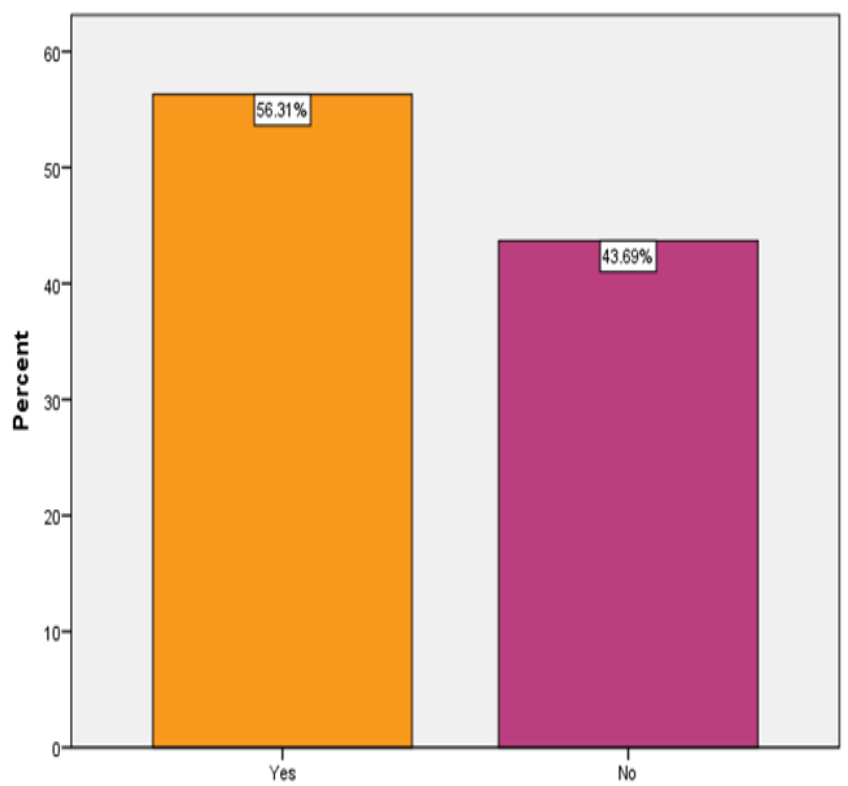

Fig 13: Ordination of respondents by Lower Back Pain. 


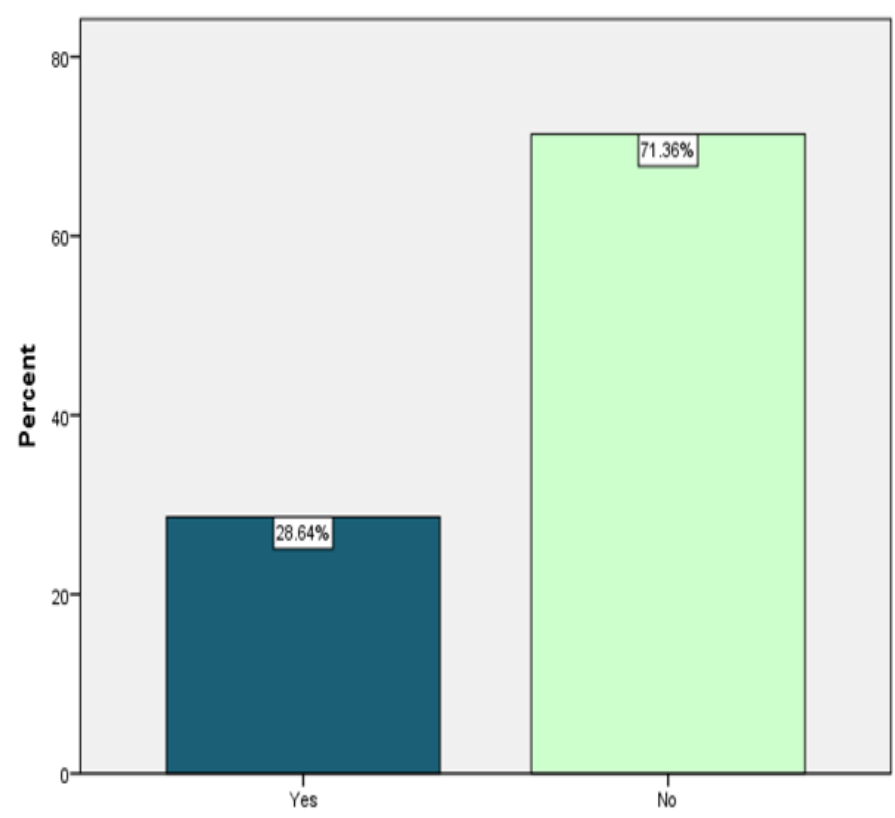

Fig 14: Respondents distribute by Upper back pain.

From the above Fig 14 explained in the upper back pain in our study. Among 206 respondents in old home area were $28.6 \%$ having pain and $71.4 \%$ have nopain.

From the above Fig 15 explained pain during sleeping time in this study. Among 206 respondents in old home area were $34 \%$ pain and $66 \%$ haven't pain during sleeping time.

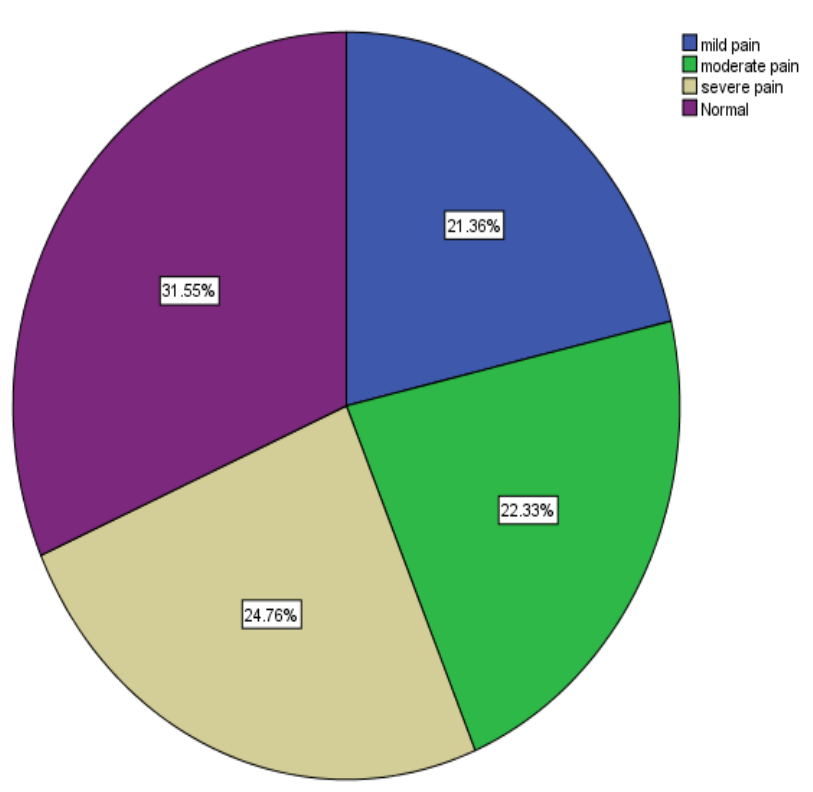

Fig 16: Distributed of respondents by Pain severity.

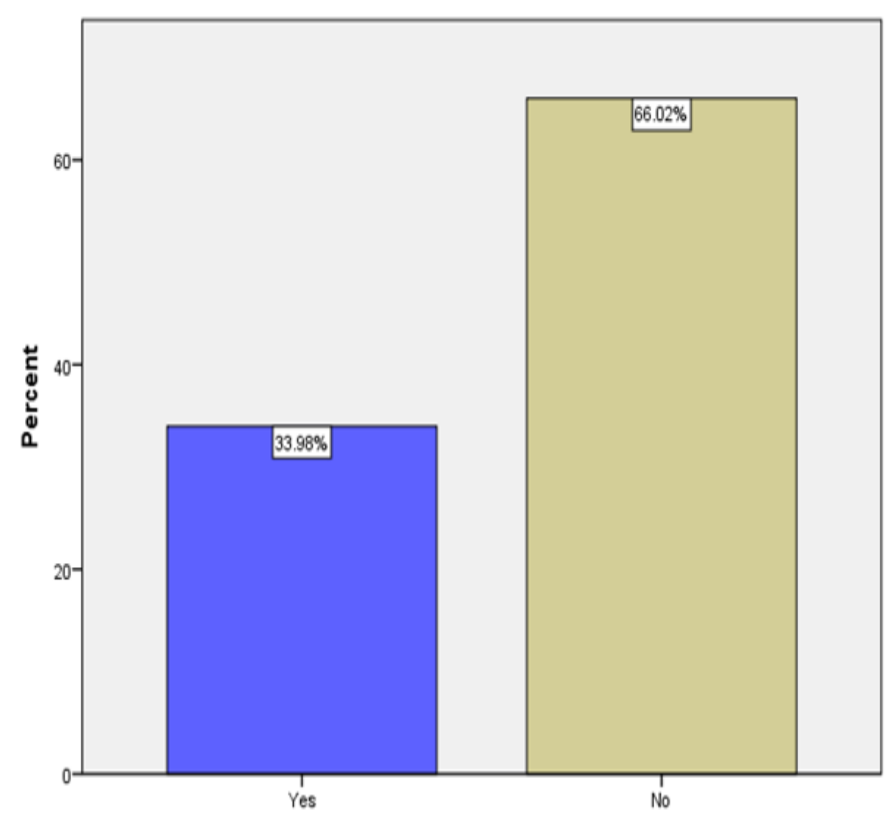

Fig 15: Respondents ordinate by Pain during sleeping time.

From the above Fig 16 explained about Pain severity in current study. Among 206 respondents in old home area were $21.36 \%$ mild, $22.33 \%$ moderate, $24.76 \%$ severe pain and $31.55 \%$ respondents have no pain.

From the above Fig 17 explained by the Stroke history in current paper. Among 206 respondents in old home area were $3.40 \%$ Right side, $4.37 \%$ left side, $2.91 \%$ both side and $89.32 \%$ have no stroke history.

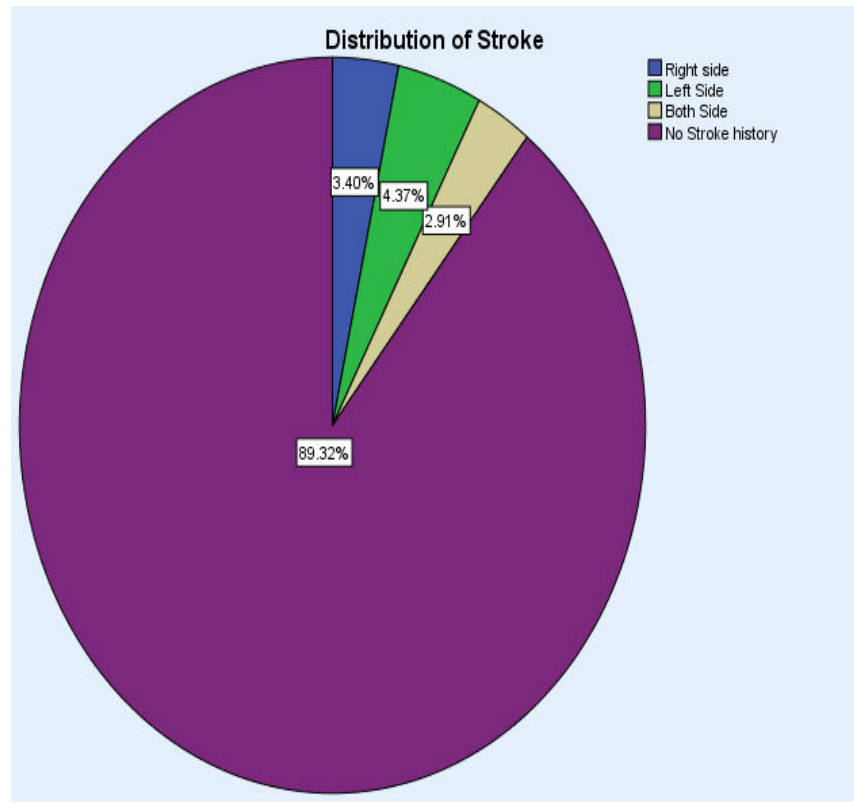

Fig 17: Ordination of respondents by Stroke history. 


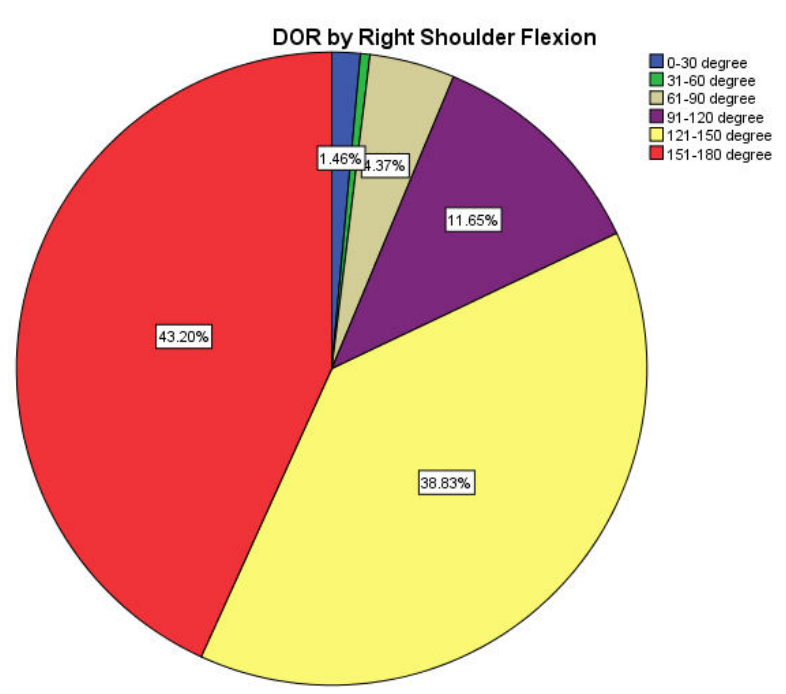

Fig 18: Distributed of respondents by Right Shoulder Flexion.

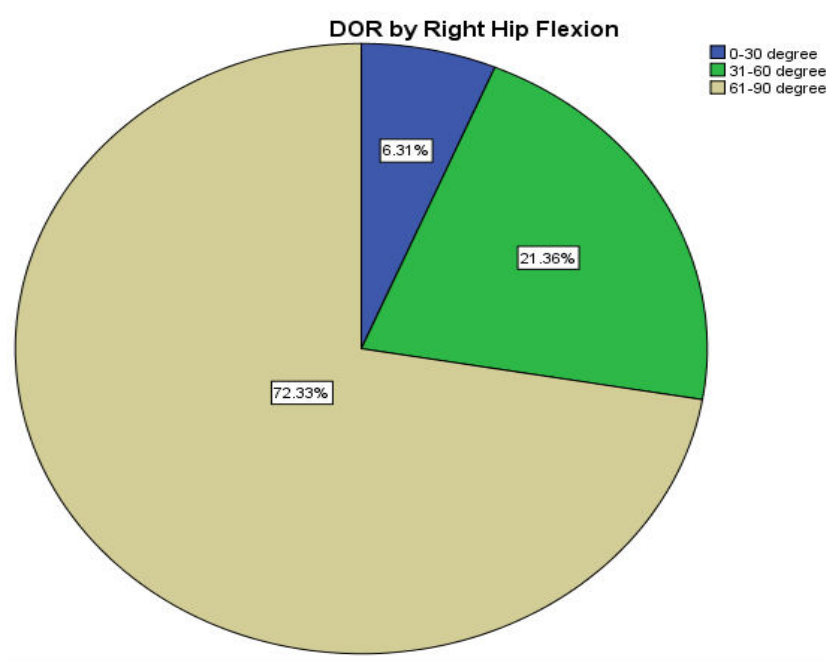

Fig 20: Distributed of respondents by Right Hip Flexion

From the above Fig 18 explained the Range of motion of Right shoulder joint flexion in our study. Among 206 respondents in old home area were $1.5 \%$ have $0^{0}$ $30^{\circ}, 0.5 \%$ have $31^{0}-60^{\circ}, 4.4 \%$ have $61^{0}-90^{\circ}, 11.7 \%$ have $91^{\circ}-120^{\circ}, 38.8 \%$ have $121^{\circ}-150^{\circ}$ and $43.2 \%$ have $151^{0}-180^{\circ}$ ROM.

From the above Fig 19 explained in the Range of motion of Left shoulder joint flexion in our study. Among 206 respondents in old home area were 1.5\% have $0^{0}-30^{\circ}, 0.5 \%$ have $31^{0}-60^{\circ}, 6.3 \%$ have $61^{0}-90^{\circ}$, $12.6 \%$ have $91^{\circ}-120^{\circ}, 40.3 \%$ have $121^{\circ}-150^{\circ}$ and $38.8 \%$ have $151^{\circ}-180^{\circ}$ ROM.

From the above Fig 20 explained to the Range of motion in Right Hip joint flexion in our study. Among UniversePG I www.universepg.com

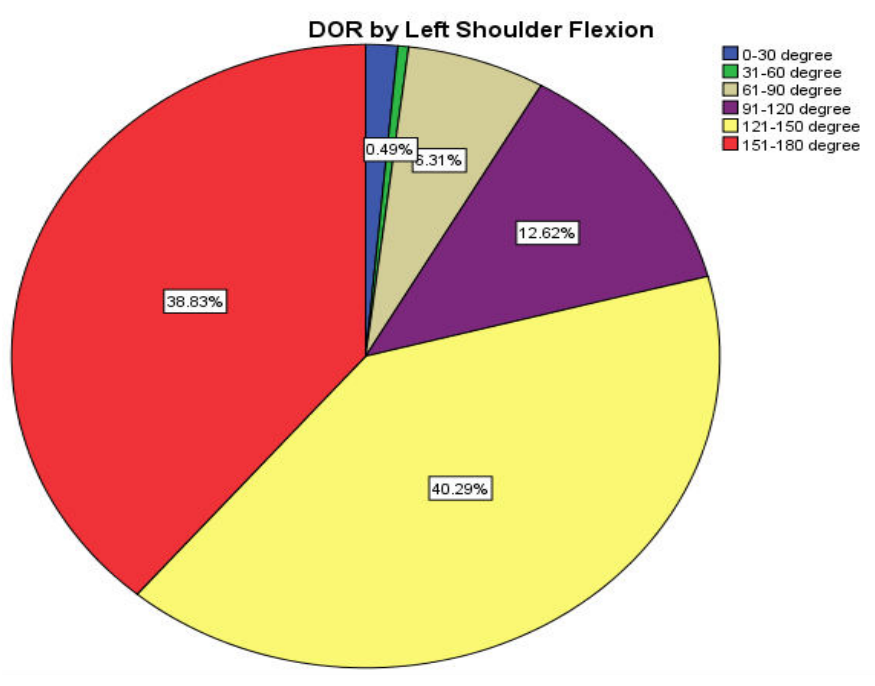

Fig 19: Respondents distribute by Left Shoulder Flexion.

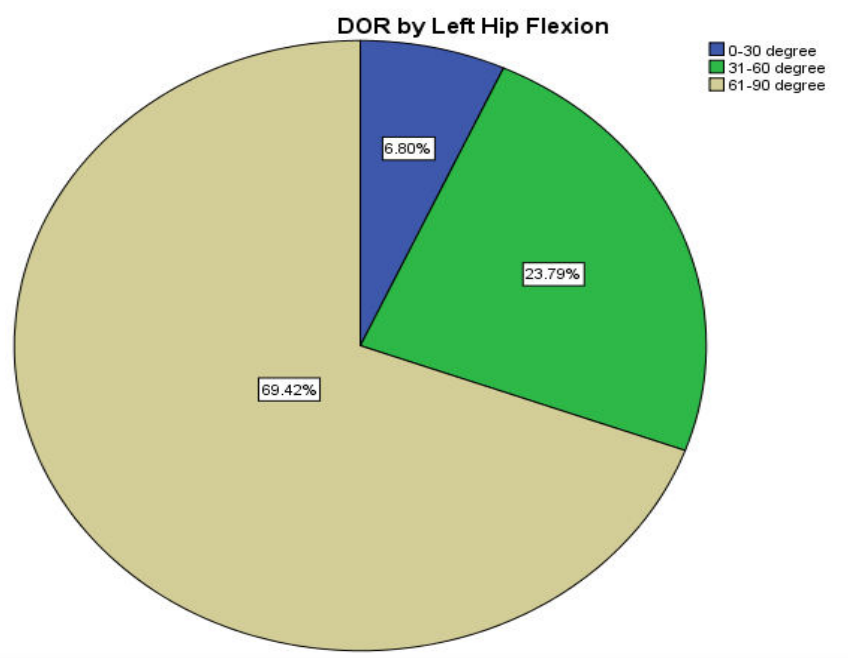

Fig 21: Ordination of respondents by Left Hip Flexion.

206 respondents in old home area were $6.3 \%$ have $0^{0}$ $30^{\circ}, 21.4 \%$ have $31^{\circ}-60^{\circ}$ and $72.3 \%$ have $61^{0}-90^{\circ}$ ROM.29

From the above Fig 21 explained by the Range of motion of Left Hip joint flexion. Among 206 respondents in old home area were $6.8 \%$ have $0^{0}-30^{\circ}$, $23.8 \%$ have $31^{0}-60^{\circ}$ and $69.4 \%$ have $61^{\circ}-90^{\circ}$ ROM.30

From the above Fig 22 explained the ROM of Right Knee joint flexion in our study. Among 206 respondents in old home area were $3.4 \%$ have $0^{\circ}-30^{\circ}$, $1.9 \%$ have $31^{0}-60^{0}, 7.3 \%$ have $61^{0}-90^{\circ}, 44.2 \%$ have $91^{\circ}-120^{\circ}$ and $43.2 \%$ have $121^{\circ}-150^{\circ}$ ROM. 


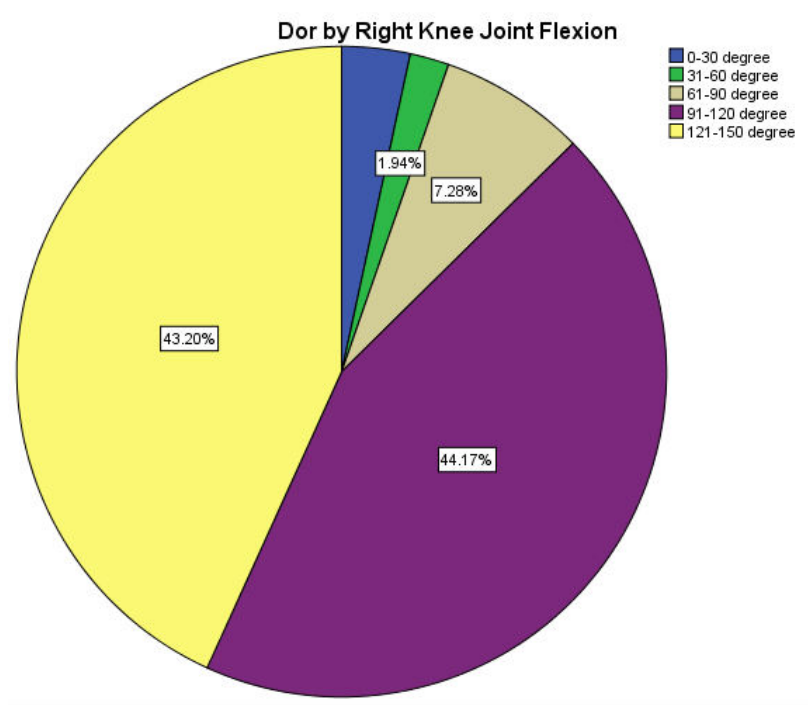

Fig 22: Distributed of respondents by Right Knee Joint Flexion.

From the above Fig $\mathbf{2 3}$ explained the Range of motion of Left Knee joint flexion in our study. Among 206 respondents in old home area were $2.4 \%$ have $0^{0}-30^{0}$, $2.4 \%$ have $31^{0}-60^{\circ}, 9.7 \%$ have $61^{0}-90^{\circ}, 42.7 \%$ have $91^{\circ}-120^{\circ}$ and $42.7 \%$ have $121^{\circ}-150^{\circ}$ ROM.

\section{DISCUSSION:}

In this paper data was collected to search the factors which are related to functional mobility to senior citizen in selected old home area in a small part in Bangladesh. This is essential to observe present situation and find out the mobility problem of aged population in selected old home. Purpose of the study is to discover the current functional status, responsible factors, activity in regular life, Health problem related factor, economical condition, functional mobility related factor, pain related factor, etc. This current paper a lot of information was presented. Here, the total 206 participants, 106 were male and 100 were female in the old home. In old home respondents are $87.9 \%$ Islam, 1.5\% Christian and $10.7 \%$ Hindu. Senior citizen age group sequentially $47.1 \%$ were 60 to 69 years old, 36.9\% were 70 to 79 years old. Only $16 \%$ were above 80 years old. Their level education, we found that $19.9 \%$ were primary level, $18.0 \%$ were SSC level, $4.4 \%$ were HSC level, $5.3 \%$ were college graduate level, $1.9 \%$ were university level, $1.5 \%$ were vocational education level and $49.0 \%$ were no education. Among 206 respondents in old home area there were $11.7 \%$ Businessman, 28. $6 \%$ job holder, $7.3 \%$ farmer, $1.9 \%$ day labor and $50.5 \%$ UniversePG I www.universepg.com

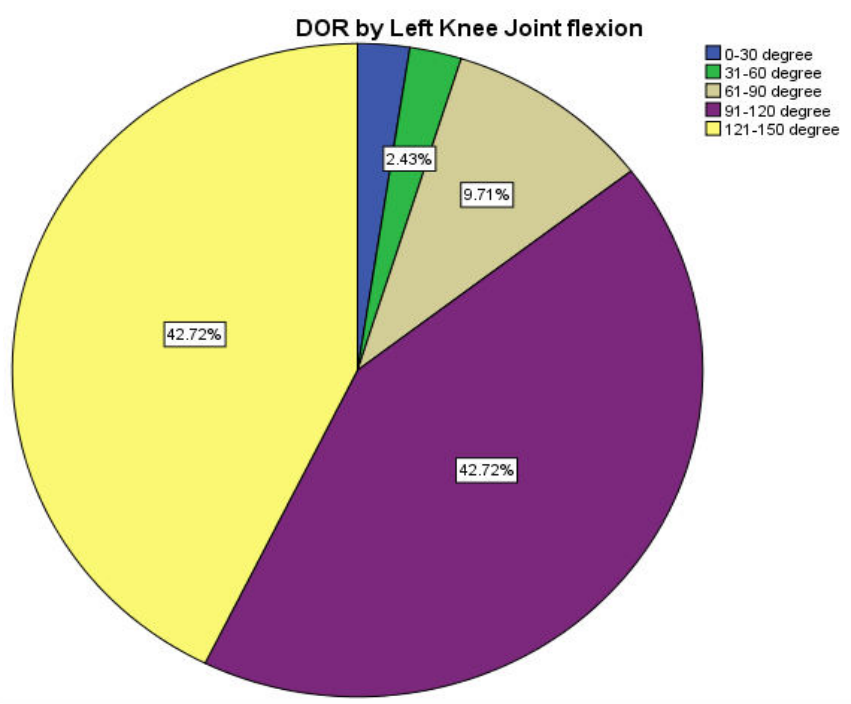

Fig 23: Ordination of respondents by Left Knee Joint Flexion.

was house worker and other occupation. Here $8.7 \%$ had income and $91.3 \%$ had no any income. Among 206 participants in our study were $74.3 \%$ have children and $25.7 \%$ have no children. Respondents reside in the old home are $26.7 \%$ live in under 1 year, $28.8 \%$ stay 1 to 2 years and $45.1 \%$ above 3 years.

Among 206 respondents of old home area, 89.3\% have self-bathing capacity and $10.7 \%$ have no capacity of self-bathing. Besides in this field $89.3 \%$ have selfdressing capacity and $10.7 \%$ have no capacity of selfdressing up. In case of toileting seen that among 206 respondents of old home area $89.8 \%$ have self-toileting capacity and $10.2 \%$ have no capacity of self-toileting. These studies among 206 respondents of old home area 93.2\% have self-washing teeth capacity and $6.8 \%$ have no capacity of self-teeth washing. Besides, in old home area $93.7 \%$ have self-eating capacity and $6.3 \%$ have no capacity of self-eating. Among 206 respondents of old home area were spend maximum time in $35.9 \%$ laying on the bed, $3.9 \%$ watching $\mathrm{TV}, 14.1 \%$ busy on work, $26.7 \%$ gossip and $19.4 \%$ spend their maximum time other works such as walking, prayer, newspaper reading, etc.

We have also obtained that among 206 respondents of old home area, $35.0 \%$ disable persons and $65.0 \%$ have no disability problem. Besides On this area respondents were use devices for disability $1.9 \%$ wheel chair, 16 . $5 \%$ stick, $1.9 \%$ crutch, $14.6 \%$ are use another de-vices. Several peoples are very sick they could not walking or 
standing. For finding out disease pattern of aged people we have asked some question and discover that among 206 participants of old home area $19.9 \%$ have diabetic mellitus and they suffered from $3.9 \%$ under 1 year, $3.9 \% 1$ to 2 years, $12.1 \% 3$ years or above. Besides, in the old home area, $51.0 \%$ respondents suffered from hypertension and $11.7 \%$ respondents suffered from low blood pressure. For finding, we are also asked some more disease related questions of all 206 participants in old home area they were $14.6 \%$ have heart problem, $64.6 \%$ have urine catching difficulty, $6.8 \%$ have kidney disease. Our review among 206 respondents of old home area were $44.2 \%$ abnormal posture and they have $36.9 \%$ Kyphosis, $4.4 \%$ Scoliosis $0.5 \%$ Lordosis and $2.4 \%$ another abnormal posture.

For finding of aged people we have asked some question for identify various pain label and its severity found that among 206 participants of old home area were $52.4 \%$ have pain during straight walking, $36.9 \%$ have neck pain, $56.3 \%$ have lower back pain, $28.6 \%$ have pain in upper back and $34.0 \%$ have pain during sleeping time. Besides On this area respondents there were pain severity $21.4 \%$ have mild pain, $22.3 \%$ have moderate pain and $24.8 \%$ have severe pain. Our research among 206 respondents of old home area was $10.7 \%$ have stroke history. Here $3.4 \%$ right side, 4.4 left side, both side $2.9 \%$ paralyses. Among 206 respondents of old home area we take their permission and measure some main joints motion by goniometry. Our findings we measure on differentiate various level of all motion. In shoulder flexion right side $1.5 \%$ was 0 to 30 degree, $0.5 \%$ was 31 to 60 degree, $4.4 \%$ were 61 to 90 degree, $11.7 \%$ were 91 to 120 degree, $38.8 \%$ were 121 to 150 degree and $43.2 \%$ were 151 to 180 degree. As opposed to shoulder flexion left side $1.5 \%$ were 0 to 30 degree, $0.5 \%$ were 31 to 60 degree, $6.3 \%$ were 61 to 90 degree, $12.6 \%$ were 91 to 120 degree, $40.3 \%$ were 121 to 150 degree and $38.8 \%$ were 151 to 180 degree.

Next we measure hip flexion right side $6.3 \%$ were 0 to 30 degree, $21.4 \%$ were 31 to 60 degree and $72.3 \%$ were 61 to 90 degree. On the other side hip flexion left side $6.8 \%$ were 0 to 30 degree, $23.8 \%$ were 31 to 60 degree and $69.4 \%$ were 61 to 90 degree.

We also measure knee flexion right side, $3.4 \%$ were 0 to 30 degree, $1.9 \%$ were 31 to 60 degree, $7.3 \%$ were 61 to 90 degree, $44.2 \%$ were 91 to 120 degree, $43.2 \%$ UniversePG I www.universepg.com were 121 to 150 degree. Contrariwise knee flexion left side, $2.4 \%$ were 0 to 30 degree, $2.4 \%$ were 31 to 60 degree, $9.7 \%$ were 61 to 90 degree, $42.7 \%$ were 91 to 120 degree, $42.7 \%$ were 121 to 150 degree. So, from this study it may be discover that more old aged people in old home area suffered from mobility problem. On this study Right shoulder motion 56.8\% participants ROM under 150 degree and Left shoulder motion 61.2\% participants ROM under 150 degree. Also Right hip motion $27.7 \%$ participants ROM under 60 degree and Left hip motion $30.6 \%$ participants ROM under 60 degree. Besides, Right knee motion $56.8 \%$ participants ROM under 120 degree and Left knee motion 57.3\% participants ROM under 120 degree. So, from this investigation majority person were suffered from postural and mobility problem.

\section{CONCLUSION AND RECOMMENDATIONS:}

To assessment on functional Activity related Disabilities among older peoples we wished to make a proposal. Than we modified and finalized our title "Prevalence of functional Activity related Mobility problem among senior citizen in selected Old Home. We selected our study area is Hotapara old home at Gazipur. It was fully for the research purpose. So we made proposal, made questionnaire, data collection directly from participants, checking, entering into computer by using SPSS 23 software, analysis and prepared result. We have finding age, educational level, daily living activities, and various disease patterns, spend time and specially try to discover the all joints ROM, Functional mobility with Disabilities. Finally overall this study it may be expressed that more old people in Gazipur old home are suffered from diabetes mellitus, HTN, movement difficulty, postural deformity, paralysis, postural deformity, mental disorder, psychological patients, back pain, muscle spasm, muscle tightness, $\mathrm{OA}$ etc.

To lead healthier and comfortable life for the aged people, there should be:

1) Provision for some form of physically active life according to their physiological capability, e.g. walking, swimming, going to gymnasium and mosque.

2) Provision for correction of abnormal posture.

3) Provision for amusement for them. 
4) Provision of pain alleviation on the degenerative disease.

5) Provision of improve ROM.

6) Provision for health education.

\section{ACKNOWLEDGEMENT:}

Special thanks to the respondents for graciously accepting to participate in this study. We would like to pay our deep respect and gratitude faculty members, Department of Physiotherapy, Gono Bishwabidyalay, Bangladesh for their continuous guidance, invaluable suggestions and affectionate encouragement at all stages of this study. We also pray deepest homage to our family members for their inspiration in our research.

\section{CONFLICTS OF INTEREST:}

We can represent our-self and our workplace. We also want positional promotion with professional background. No potential conflicts of interest to publish it.

\section{REFERENCE:}

1) Aftab E, Patla A, Cook S. (1999). japa. 7(1): 7-19. https://doi.org/10.1123/japa.7.1

2) Alan M. Jette. (2009). joga. 64(11): 11651168. https://doi.org/10.1093/gerona/glp093

3) Applegate, William B.; Glass, John P.; Williams, Franklin T. (1990). Instruments for the In: New England Journal of Medicine 322, 1207-1214.

https://link.springer.com/chapter/10.1007/978-3322-90446-1 7

4) Arksey, H., \& O' Malley, L. (2005). Scoping Studies: Towards a Methodological Framework. International Journal of Social Research Methodology: Theory \& Practice, 8(1), 19-32. https://doi.org/10.1080/1364557032000119616

5) Berg KO, Maki BE, Williams JI, P J Holliday, Wood-Dauphinee SL. (1992). Arch Phys Med Rehabil 73; pp. 1073-80. https://pubmed.ncbi.nlm.nih.gov/1444775

6) Brault M.W, Hootman J, Helmick C.G, Theis K.A, Armour, B.S. (2009). Mortality and Morbidity Weekly Report; 58(16): 421-426. https://www.cabdirect.org/abstract/20093170824

7) Campbell A J, Borrie M J, Spears G F. (1989). J Gerontol, 44; pp. M112-7. https://doi.org/10.1093/geronj/44.4.m112

UniversePG I www.universepg.com
8) Chiu AY, Au-Yeung SS, Lo SK. (2003). Disabil Rehabil, 25; pp. 45-50.

https://pubmed.ncbi.nlm.nih.gov/12554391

9) Davis J W, Ross P D, Nevitt M C, Wasnich R D. (1999). J Am Geriatr Soc, 47; pp. 792-8. https://doi.org/10.1111/j.1532-5415.1999.tb038 $\underline{34 . \mathrm{x}}$

10) Donald J. Lollar, (2002). Public health and disability: emerging opportunities. Public Health Reports. 117(2):131-136. https://doi.org/10.1093/phr/117.2.131

11) Field J. M, Jette M. (2007). Washington (DC): National Academies Press (US). https://pubmed.ncbi.nlm.nih.gov/20669428

12) Iris Tamara Schneider, Gabriele Meyer, (2014). Session presented on Monday, November 9, 2015 Clark open Access/Academic Literature Review First online. 30 August 2014.

13) Jason E Lang, Lynda Anderson, James Logerfo, Joseph Sharkey, Elaine Belansky, Lucinda Bryant, Tom Prohaska, Mary Altpeter, Victor Marshall, William Satariano, Susan Ivey, Constance Bayles, Delores Pluto, Sara Wilcox, R Turner Goins, Robert C Byrd, (2006). Prev Chronic Dis. 3(1):A17. https://pubmed.ncbi.nlm.nih.gov/16356370/

14) Leinonen R., Heikkinen E., Hirvensalo M, T Lintunen, M Rasinaho, R Sakari-Rantala, M Kallinen, J Koski, S Möttönen, S Kannas, P Huovinen, Rantanen T. (2006). Scandinavian journal of medicine \& science in sports 17(2), 156-164. https://doi.org/10.1111/j.1600-0838.2006.00536.x

15) Lord SR, Ward JA, Williams P. K J Anstey. J (1994). Am Geriatr Soc, 42; pp. 1110-7. https://doi.org/10.1111/j.1532-5415.1994.tb0621 8.x

16) Luukinen H, Koski K, Laippala P, Kivela S L. (1995). Scand J Prim Health Care, 13, pp. 2949. https://doi.org/10.3109/02813439508996778

17) Marian Giné-Garriga, Marta Roqué-Fíguls, Laura Coll-Planas, MercèSitjà-Rabert, Antoni Salvà, (2014). apmr 95(4), 753-769.

18) Meg E Morris, Brooke Adair, Kimberly Miller, Elizabeth Ozanne, Ralph Hansen, Alan J Pearce, Nick Santamaria, Luan Viega, Maureen 
Long, Catherine M. (2013). Said Journal of aging science 1(1), 1-9.

https://dro.deakin.edu.au/eserv/DU:30059059/pea rce-smarthometechnologies-2013

19) Nevitt M C, Cummings S R, Kidd S, Black D. (1989). JAMA, 261; pp. 2663-8.

https://pubmed.ncbi.nlm.nih.gov/2709546

20) Physical Activity Guidelines Advisory Committee Report (PAGACR), (2008). USA. https://pubmed.ncbi.nlm.nih.gov/19178654

21) Prohaska T, Belansky E, Belza B, Buchner D,Marshall V, McTigue K, Satariano W, Wilcox S. (2006). J Gerontol B Psychol Sci Soc Sci. 61(5): S267-73.

https://pubmed.ncbi.nlm.nih.gov/16960240

22) Rana $S$, Hossen $M$, Islam $A$, Shah $S$, Parvin $T$, Muraduzzaman SM, and Jalali MA. (2021). Interpretation of the common MRI findings in patients with painful knee joint, Eur. J. Med. Health Sci., 3(1), 19-26.

https://doi.org/10.34104/ejmhs.021.019026

23) Reuben DB, Siu AL. (1990). J Am Geriatr So, 38; pp. 1105-12. https://doi.org/10.1111/j.1532-5415.1990.tb013 73.

24) Rimmer JH, Chen M-D, McCubbin JA, Drum C, Peterson J. (2010). American Journal of Physical Medicine \& Rehabilitation/Association; 89(3): 249-63. https://doi.org/10.1097/PHM.0b013e3181c9fa9d
25) Roy K, Hossain S, Lilon MAA, Yasmin N, Sarkar S, Roy K, Haque A, Jobayer M, Saha B, and Roy RC. (2020). Assessment of depression among musculoskeletal fracture patients in a tertiary referral hospital in Bangladesh, Eur. $J$. Med. Health Sci., 2(6), 134-144. https://doi.org/10.34104/ejmhs.020.01340144

26) Stephen R Lord, Anne Tiedemann, Chapman K, Munro B, Susan M Murray, M Gerontology, G R ther, Sherrington C. (2005). J Am Geriatr Soc, 53; pp. 1296-304.

https://doi.org/10.1111/j.1532-5415.2005.53425.x

27) Teresa E Seeman, Sharon S Merkin, Eileen M Crimmins, Arun S Karlamangla, (2010). American J. of Public Health; 100(1): 100-107. https://doi.org/10.2105/AJPH.2008.157388

28) Teresa M. Jimenez Bunuales, Paulino Gonzalez Diego, Jose M Martin Moreno. (2002). Rev Esp Salud Publica. 76(4): 271-9. https://doi.org/10.1590/s1135-57272002000400 $\underline{002}$

29) Tinetti ME, Speechley M, Ginter SF. (1988). Engl J Med. 319(26): 1701-7. https://pubmed.ncbi.nlm.nih.gov/3205267

30) Tinetti ME. (1986). Am Geriatr Soc, 34; pp. 119-26. https://doi.org/10.1111/j.1532-5415.1986.tb054 $\underline{80 . x}$

Citation: Chowdhury MOSA, Khatun R, and Pervin S. (2021). Prevalence of physical activity with mobility disabilities among senior citizens in a selected old home. Eur. J. Med. Health Sci., 3(5), 88-102. https://doi.org/10.34104/ejmhs.021.0880102 @) 